\title{
Ottawa passes drug safety law
}

$\mathrm{N}$ ew drug safety legislation is on its way to the Senate after being unanimously approved in the House of Commons.

Bill C-17, which amends the Food and Drugs Act, would give the minister of health authority to order a drug off the market if surveillance data suggest a serious risk - a power most regulators in other countries already have. Health Canada currently negotiates with the drug's manufacturer to add stronger warnings to labels or to voluntarily withdraw the product.

If approved by the Senate, the legislation would also enable Health Canada to order manufacturers to amend labelling, to provide information to determine safety, and to monitor and report on post-market safety. The bill provides for fines of up to $\$ 5$ million a day or an unlimited amount for companies that market unsafe products.

Prior to the House of Commons vote, Bill $\mathrm{C}-17$ was amended to allow the federal government to make public the reasons behind its decisions to approve, reject or recall a drug. If a drug poses a serious risk to human health, the amendments also permit the government to disclose confidential business information without telling the manufacturer and to register and report the outcomes of clinical trials and observational studies.

Under Canada's current regulatory regime, many of these transparency provisions are voluntary.

After the Senate has considered the bill - also known as Vanessa's Law - it can receive royal assent and become law, likely this fall.

Conservative MP Terence Young, whose daughter Vanessa's death inspired the legislation, says "Once it's fully implemented, up to $70 \%$ of the adverse drug reactions that either kill Canadian patients or harm them could be prevented."

Despite Young's optimism, experts in law and medicine warn that the key to truly bolstering Health Canada's powers to protect patients from unsafe drugs is in the regulations the department must draft to accompany the law.

None of the enforcement provisions

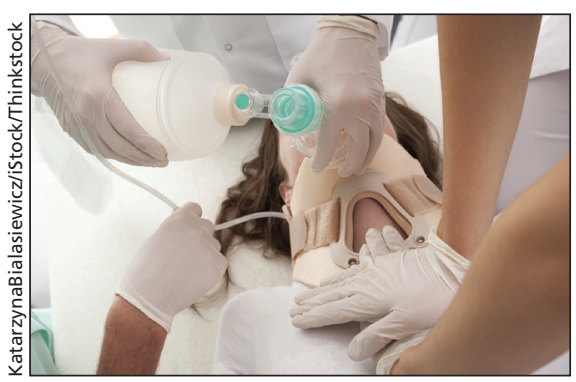

Bill C-17 allows Ottawa to remove a drug from market if there are serious risks.

around transparency is in the legislation as it is currently written.

During testimony to the parliamentary Standing Committee on Health in early June, Matthew Herder, an assistant professor in medicine and law at Dalhousie University in Halifax, urged the government to make registration of all clinical trials and investigational studies plus reporting of study results mandatory and specified in the law. This would give the regulator the power to withhold licensing if a company did not comply. $\mathrm{He}$ also advocated for fines.

After Senate approval, it will be up to Health Canada to draft regulations stringent enough to give the legislation teeth. That's a process that Herder and his colleagues, and the pharmaceutical industry, will be watching closely.

"In spirit, we are supportive [of the bill]," says Walter Robinson, vice-president of government affairs for Rx\&D, Canada's Research-Based Pharmaceutical Companies. "We need to take a look at the actual details of the regulatory amendments themselves."

He urged Health Canada to work with regulators in other jurisdictions to ensure that the new regulations are consistent with those in the United States, the European Union and other markets where multinational drug companies apply to license their drugs.

The proposed legislation formalizes the way the companies already operate in Canada, says Robinson, but Health Canada officials will have to make sure the regulations are consistent with international trade agreements and other existing legislation, he cautioned. - Laura Eggertson, Ottawa, Ont.

CMAJ 2014. DOI:10.1503/cmaj.109-4834 